\title{
C19MC Amplification
}

National Cancer Institute

\section{Source}

National Cancer Institute. C19MC Amplification. NCI Thesaurus. Code C129498.

A genetic finding indicating the presence of amplification of the C19MC region on

chromosome 19 (19q13.42). 